\title{
Association of aldehyde dehydrogenase 2 gene polymorphism with multiple oesophageal dysplasia in head and neck cancer patients
}

\author{
M Muto, Y Hitomi, A Ohtsu, S Ebihara, S Yoshida, H Esumi
}

Department of Gastrointestinal Oncology and Gastroenterology, National Cancer Center Hospital East, Kashiwa, Japan

M Muto

A Ohtsu

S Yoshida

Investigative Treatment Division, National Cancer Center Research Institute East, Kashiwa, Japan Y Hitomi

$\mathrm{H}$ Esumi

Department of Head and Neck Surgery,

National Cancer Center Hospital East, Kashiwa, Japan S Ebihara

Correspondence to: Dr M Muto, Department of Gastrointestinal Oncology and Gastroenterology, National Cancer Center Hospital East, 6-5-1 Kashiwanoha, Kashiwa 277-8577, Japan.

Email:mmuto@east.ncc.go.jp

Accepted for publication 8 February 2000

\begin{abstract}
Background-Multiple occurrences of oesophageal dysplasia are frequently observed in head and neck cancer patients, and closely associated with alcohol consumption. Acetaldehyde, the first metabolite of ethanol, is thought to play an important role in the carcinogenesis of the upper aerodigestive tract.

Aim-To investigate if genetic polymorphism in alcohol metabolising enzymes (ADH3, alcohol dehydrogenase 3; ALDH2, aldehyde dehydrogenase 2) is associated with oesophageal multiple dysplasia in head and neck cancer patients.

Methods-Thirty one consecutive patients with head and neck cancer were included in the study. Multiple oesophageal dysplasia was detected endoscopically as multiple Lugol voiding lesions (multiple LVL) using the Lugol dye staining method. The $A D H 3$ and $A L D H 2$ genotypes were determined by polymerase chain reactionrestriction fragment length
\end{abstract} polymorphism.

Results-Among the 31 patients with head and neck cancer, 17 had multiple LVL. Multiple LVL were closely associated with a second primary oesophageal carcinoma in head and neck cancer patients (odds ratio $60.7,95 \%$ CI 5.6-659). Furthermore, the mutant $A L D H 2$ allele was significantly more prevalent in patients with multiple LVL $(65 \%$ v $29 \%$; $<0.05)$ whereas no difference was observed in $\mathrm{ADH} 3$ polymorphism.

Conclusions-The mutant $A L D H 2$ allele appears to be a risk indicator for multiple LVL in head and neck cancer patients. Accumulation of acetaldehyde due to low ALDH2 activity may play a critical role in cancerous changes throughout the mucosa in the upper aerodigestive tract. (Gut 2000;47:256-261)

Keywords: head and neck cancer; oesophageal carcinoma; alcohol dehydrogenase; aldehyde dehydrogenase; multiple dysplasia; Lugol voiding lesion

Squamous epithelial cell dysplasia has a high potential to progress to malignancy. Premalignant lesions of squamous cell carcinoma in the upper aerodigestive tract are similar to those in the neck of the uterus and skin. ${ }^{1-3}$ Dysplastic lesions and squamous cell carcinoma of the oesophagus can be easily detected endoscopi- cally by spraying Lugol dye solution ${ }^{4}$ : the dye reacts with glycogen in the cells of the normal epithelium and leaves dysplastic and cancerous lesions unstained.

In patients with head and neck cancer, we often encountered an unusual endoscopic finding in that a larger number of Lugol unstained lesions spread throughout the oesophageal mucosa. This endoscopic finding was rare in other patients, and we discriminated these multiple Lugol voiding lesions (multiple LVL) from a common single Lugol unstained lesion. As similar lesions surrounding the surgically resected oesophageal carcinoma were frequently observed in patients with a second primary head and neck cancer, ${ }^{5}$ such lesions were thought to be related to the development of squamous cell carcinoma in the oesophagus. Therefore, we thought it would be useful to determine the aetiology of multiple LVL in head and neck cancer patients.

Regarding multiple occurrences of neoplastic changes in the upper aerodigestive tract, genetic and/or environmental factors are considered to play an important role in the pathogenesis. However, to date, genetic abnormalities (such as replication errors and p53 mutation) have not been associated with this lesion. ${ }^{6-8}$ Alcohol consumption and cigarette smoking are generally accepted as major environmental risk factors for single and multiple occurrences of head and neck cancer and oesophageal cancer. ${ }^{5-11}$ Acetaldehyde, the first oxidative metabolite of ethanol, is recognised as a carcinogen and has a tumour promoting effect on the upper aerodigestive tract in experimental animal models ${ }^{12}{ }^{13}$ although the precise mechanism is unknown. The in vivo concentration of acetaldehyde depends on the activities of two ethanol metabolising enzymes, alcohol dehydrogenase (ADH) and aldehyde dehydrogenase (ALDH), which oxidise ethanol to acetaldehyde and acetaldehyde to acetate, respectively. ${ }^{14}$

It was recently reported that individuals homozygous for the genotype $A D H 3^{1-1}$ have an increased risk of alcohol related oral and pharyngeal cancers. ${ }^{15}$ In Japanese alcoholics, the mutant $A L D H 2$ allele, which is found only in Orientals at a frequency of approximately $50 \%$ and associates with intolerance to alcohol,

Abbreviations used in this paper: $\mathrm{ADH} 3$, alcohol dehydrogenase 3; ALDH2, aldehyde dehydrogenase 2; LVL, Lugol voiding lesion; PCR-RFLP, polymerase chain reaction-restriction fragment length polymorphism. 


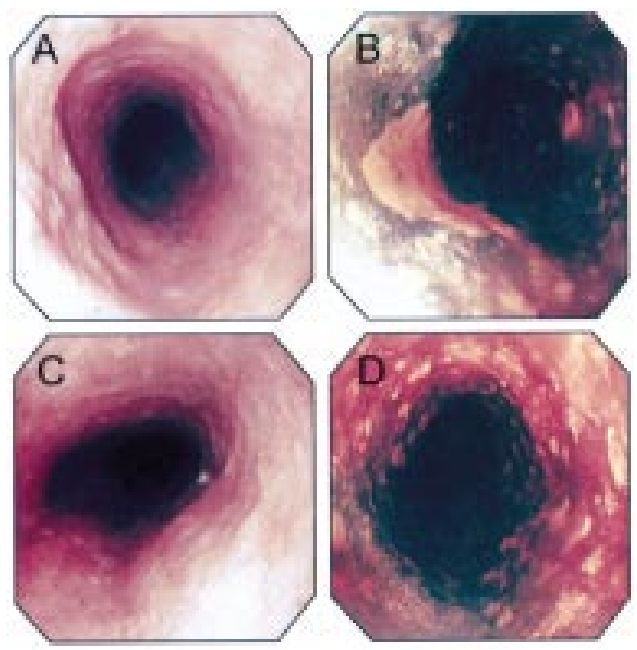

Figure 1 Endoscopic images of the oesophagus in a patient with head and neck cancer $(A-D)$. Conventional endoscopic images $(A, C)$ showed no abnormalities. After application of Lugol dye solution, multiple well defined, irregular shaped, yellowish white multiple Lugol voiding lesions (LVL) were seen scattered throughout the oesophageal mucosa $(B, D)$.

was also reported to be a risk factor for multiple cancers of the upper aerodigestive tract. ${ }^{16-18}$

In this study, we assessed the association of multiple LVL with the occurrence of a second primary oesophageal cancer and genetic polymorphism of the $A D H 3$ and $A L D H 2$ genes, in patients with head and neck cancer.

\section{Methods}

PATIENTS

Thirty one consecutive patients $(27$ men, four women; mean age 63 years (SD 10)) with head and neck cancer who underwent oesophagoscopy at the Department of Gastrointestinal Oncology and Gastroenterology, National Cancer Center Hospital East, Japan, were screened using the endoscopic Lugol dye staining method and the polymerase chain reaction-restriction fragment length polymorphism (PCR-RFLP) method. In this study, the anatomical sites of head and neck cancer included only the oropharyngolaryngeal region: 15 had pharyngeal or larynx cancer, and the remaining 16 had cancer of the oral cavity. All head and neck cancers were histologically confirmed to be squamous cell carcinomas. We used the same questionnaire to define drinking and smoking habits, and family history of cancer for all patients. Patients who abstained from drinking any alcoholic beverage and from cigarette smoking throughout their life were classified as non-drinkers and non-smokers. Daily alcohol consumption was calculated as grams per day. All biopsy samples were obtained with informed consent and in accordance with the Helsinki Declaration.

\section{ENDOSCOPIC SCREENING METHODS AND}

DEFINITION OF MULTIPLE LVI

Endoscopic screening of multiple LVL in the oesophagus was performed using the Lugol dye staining method, as described previously, ${ }^{19}$ using an electronic endoscope (Q230, Olympus Optical Co. Ltd, Tokyo, Japan). When a large number of well defined irregular shaped Lugol unstained lesions were observed endoscopically throughout the entire oesophageal mucosa after application of the Lugol dye solution, the patient was defined as having multiple LVL (fig 1).

\section{TISSUE SAMPLE COLLECTION}

Normal oesophageal tissues that stained positively with Lugol dye solution were collected endoscopically. Samples were stored at $-80^{\circ} \mathrm{C}$ until analysis. Genomic DNA was prepared from biopsy specimens by conventional phenol-chloroform extraction. The amount of DNA was determined spectrophotometrically.

PCR-RFLP ANALYSIS OF ADH3 GENE POLYMORPHISM

The $A D H 3$ genotype was determined using PCR-RFLP. ${ }^{20}$ Genomic DNA was initially digested with NlaIII (TOYOBO, Osaka, Japan) to prevent amplification of closely related $A D H 1$ and $A D H 2$ genes. PCR was performed in a $50 \mu \mathrm{l}$ volume of PCR mixture containing $100 \mathrm{ng}$ of DNA, $10 \mathrm{mM}$ Tris $\mathrm{HCl}(\mathrm{pH} \mathrm{8.3),} 50$ $\mathrm{mM} \mathrm{KCl}, 3 \mathrm{mM} \mathrm{MgCl}_{2}, 50$ pmol of each primer (sense: 5'-GCTTTAAGAGTAAATA TTCTGTCCC-3'; antisense: 5'-AATCTACC TCTTTCCGAAGC-3'), $250 \mu \mathrm{M}$ of each dNTP, and $5 \mathrm{U}$ of Taq polymerase (Takara Shuzo, Kyoto, Japan) using a DNA thermal cycler (Perkin-Elmer Corp., Norwalk, Connecticut, USA). The cycling conditions were: 35 cycles of 30 seconds for denaturation at $94^{\circ} \mathrm{C}, 30$ seconds for annealing at $55^{\circ} \mathrm{C}$, and 30 seconds for extension at $72^{\circ} \mathrm{C}$, followed by a final extension at $72^{\circ} \mathrm{C}$ for 10 minutes. PCR products were digested with SspI (TOYOBO, Osaka, Japan), electrophoresed on a $10 \%$ polyacrylamide gel, stained with ethidium bromide, and viewed under ultraviolet light.

\section{PCR-RFLP ANALYSIS OF $A L D H 2$ GENE}

POLYMORPHISM

$A L D H 2$ genotyping was performed by PCRRFLP according to the method of Harada and Misawa $^{21}$ with a slight modification. PCR was performed in a $50 \mu \mathrm{l}$ volume of PCR mixture containing $100 \mathrm{ng}$ of DNA, $10 \mathrm{mM}$ Tris $\mathrm{HCl}$ (pH 8.3), $50 \mathrm{mM} \mathrm{KCl}, 1.5 \mathrm{mM} \mathrm{MgCl}, 5$ pmol of each primer (sense: 5'-CAAATTACAG GGTCAAGGGCT-3'; antisense: 5'-CCACAC TCACAGTTTTCTCTT-3'), $50 \mu \mathrm{M}$ of each dNTP, and 1 U of Taq polymerase (Takara Shuzo, Kyoto, Japan) using the GeneAmp PCR system 9600 (Perkin-Elmer Corp.). The cycling conditions were: 35 cycles of 15 seconds for denaturation at $94^{\circ} \mathrm{C}, 45$ seconds for annealing at $55^{\circ} \mathrm{C}$, and 30 seconds for extension at $72^{\circ} \mathrm{C}$, followed by a final extension at $72^{\circ} \mathrm{C}$ for 10 minutes. PCR products were digested with $M b o \mathrm{II}$ (TOYOBO, Osaka, Japan) and separated on a $10 \%$ polyacrylamide gel.

\section{STATISTICAL ANALYSIS}

We used the Student's $t$ test to test for differences among continuous variables. Fisher's exact test was also used to compare patient characteristics. Significance was assigned to 
Table 1 Characteristics of head and neck cancer patients with or without multiple Lugol voiding lesions (LVL)

\begin{tabular}{|c|c|c|c|}
\hline & \multicolumn{3}{|l|}{ Multiple LVL } \\
\hline & Without $(n=14)$ & With $(n=17)$ & p Value \\
\hline Sex & & & $<0.05$ \\
\hline Male & 10 & 17 & \\
\hline Female & 4 & 0 & \\
\hline Age (mean (SD)) & $59.8(10.3)$ & $65.1(8.6)$ & NS \\
\hline \multicolumn{4}{|l|}{ Primary tumour site of $\mathrm{HNC}$} \\
\hline Tongue & 5 & 3 & \\
\hline Pharynx/larynx & 6 & 9 & NS \\
\hline Other oral cavity & 3 & 4 & NS \\
\hline Drinking habits & & & NS \\
\hline Non-drinkers & 2 & 2 & \\
\hline Drinkers & 15 & 12 & \\
\hline \multicolumn{4}{|l|}{ Most often consumed drink } \\
\hline Beer & 3 & 2 & \\
\hline Sake (a typical Japanese liquor) & 7 & 7 & NS \\
\hline Whisky & 2 & 5 & NS \\
\hline Daily alcohol intake (g) (mean (SD)) & $60.3(54)$ & $68.0(51)$ & \\
\hline Smoking habits & & & $<0.05$ \\
\hline Non-smokers & 4 & 0 & \\
\hline Smokers & 10 & 17 & \\
\hline \multicolumn{4}{|l|}{ Brinkman index } \\
\hline 0 & 4 & 0 & \\
\hline 0 to $\leqslant 400$ & 0 & 2 & NS \\
\hline $400<$ & 10 & 15 & NS \\
\hline Family history of cancer & & & NS \\
\hline Present & 5 & 9 & \\
\hline Absent & 9 & 8 & \\
\hline Second primary oesophageal cancer & & & $<0.0001$ \\
\hline Present & 1 & 14 & \\
\hline Absent & 13 & 3 & \\
\hline
\end{tabular}

values of $p<0.05$. Associations between putative risk factors and multiple LVL were assessed as odds ratios (OR).

\section{Results}

CLINICOPATHOLOGIAL FEATURES OF MULTIPLE

LVL

Among the consecutive 31 head and neck cancer patients, 17 showed a large number of well defined irregular shaped Lugol unstained lesions throughout the oesophageal mucosa after application of Lugol dye solution (fig 1B, D). These lesions were difficult to detect on conventional endoscopic examination (fig 1A, C). All 17 patients showed similar endoscopic findings and were defined as having multiple LVL. In contrast, definite Lugol unstained lesions were hardly detected in the remaining 14 patients with head and neck cancer and these patients were defined as not having multiple LVL. Accordingly, we divided our 31 head and neck cancer patients into two groups. There were no differences in sex, age, or primary site of the head and neck cancer between these two groups (table 1).

On histological examination, several biopsy specimens of Lugol unstained lesions taken from all patients with multiple LVL showed severe dysplasia (fig 2A). The large Lugol unstained lesion in fig $1 \mathrm{~B}$ was diagnosed as a squamous cell carcinoma in situ (fig 2B).

ASSOCIATION OF MULTIPLE LVL WITH THE SECOND PRIMARY OESOPHAGEAL CANCER IN HEAD AND NECK CANCER PATIENTS

To clarify the significance of multiple LVL in head and neck cancer patients, we examined its association with the second primary oesophageal cancer (table 1). The second primary oesophageal cancer was found in $82 \%(14 / 17)$ of head and neck cancer patients with multiple

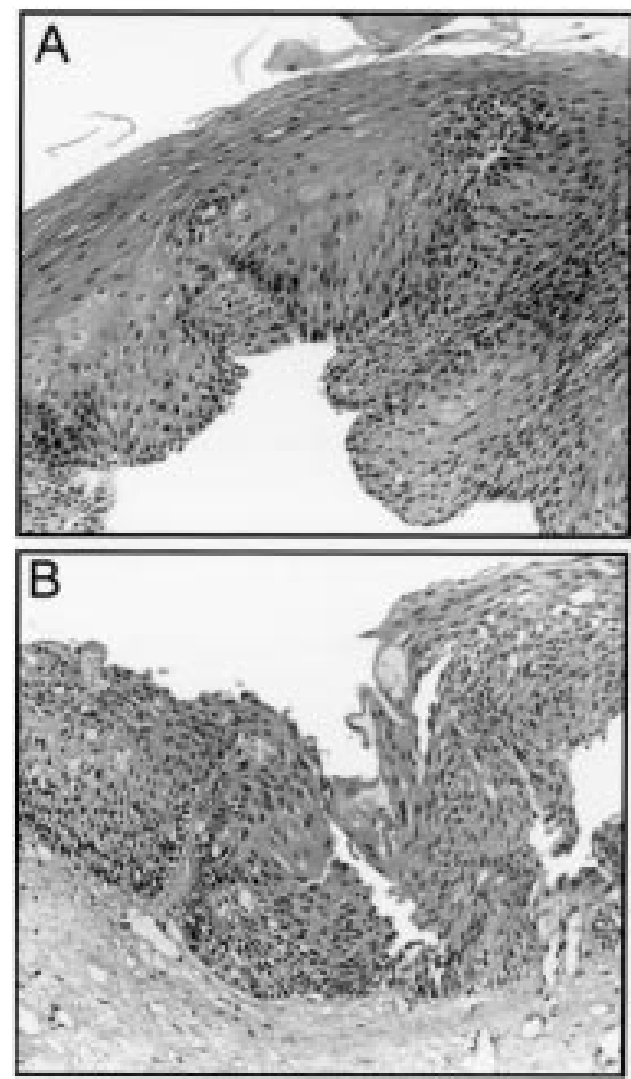

Figure 2 Histological examination of multiple Lugol voiding lesions (LVL). The biopsy specimen taken from some of the multiple LVL showed severe dysplasia $(A)$. The endoscopically resected specimen of the largest LVL in fig $1 B$ revealed squamous cell carcinoma in situ (B).

LVL whereas only $7 \%(1 / 14)$ of those without multiple LVL had oesophageal cancer $(p<0.0001$; OR 60.7, 95\% CI 5.6-659.3). Furthermore, three of the head and neck cancer patients with multiple LVL had double oesophageal cancer and more than half of the oesophageal cancers concomitant with head and neck cancer were superficial carcinomas $(73 \% ; 11 / 15)$. This strong association of multiple LVL with the second primary oesophageal cancer suggests that multiple cancerous changes occurred throughout the mucosa of the upper aerodigestive tract in some patients with head and neck cancer.

ASSOCIATION OF GENETIC POLYMORPHISMS OF ALCOHOL METABOLISING ENZYMES WITH MULTIPLE LVL

To assess possible genetic and environmental factors responsible for the extensive mucosal changes in the oesophagus, we first compared drinking habits between head and neck cancer patients with multiple LVL and those without (table 1). There were no differences in drinking habits (daily alcohol consumption and type of alcoholic beverage) between the two groups. Almost all patients in both groups were defined as drinkers, drinking more than five days a week. To clarify this point further in terms of alcohol metabolism, we examined the associations of $A D H 3$ and $A L D H 2$ gene polymorphism with multiple LVL. 


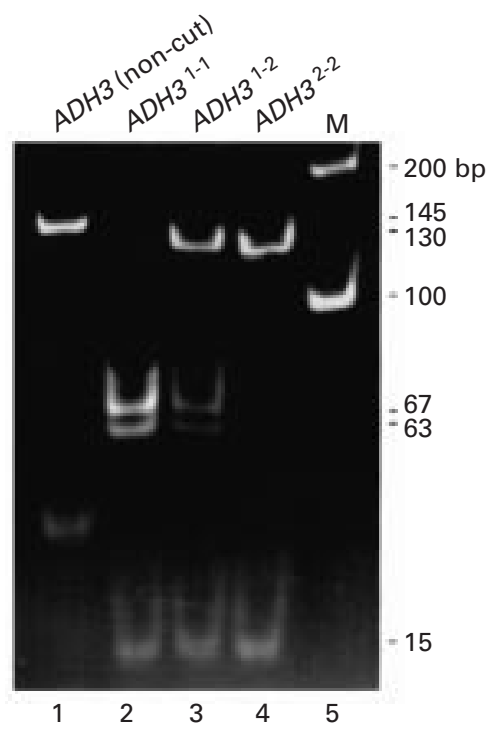

Figure 3 Representative electrophoretic patterns of the ADH3 genotype analysed by polymerase chain reaction-restriction fragment length polymorphism (PCR-RFLP) from three patients with the ADH $3^{1-1}$ $A D H 3^{1-2}$, and $A D H 3^{2-2}$ genotypes. The ADH $3^{1}$ allele yielded $67 \mathrm{bp}, 63 \mathrm{bp}$, and $15 \mathrm{bp}$ fragments, and the $\mathrm{ADH}$ allele appeared as a $130 \mathrm{bp}$ and a $15 \mathrm{bp}$ fragment. The undigested PCR product for $A D H 3$ (ADH3 non-cut) is shown for comparison (lane 1). A 100 bp marker ladder served as a reference for DNA fragment size (M, lane 5).

The $A D H 3$ gene polymorphism was divided into two groups: individuals homozygous for the fast metabolising $A D H 3^{1}$ allele $\left(A D H 3^{1-1}\right)$ and those who had the slow metabolising $A D H 3^{2}$ allele $\left(A D H 3^{1-2}\right.$ or $\left.A D H 3^{2-2}\right)$. PCRRFLP analysis discriminated between the following genotypes: $A D H 3^{1-1}, A D H 3^{1-2}$, and $A D H 3^{2-2}$, as shown in fig 3 (lanes 2,3 , and 4 , respectively). The frequency of the slow metabolising $A D H 3^{2}$ allele in this study was $12.9 \%(4 / 31)$ which was slightly higher than a previous report of $5 \%$ in Japanese subjects. ${ }^{22}$ However, no difference was observed in the allelic frequency of the $A D H 3$ gene between head and neck cancer patients with and without multiple LVL (table 2).

PCR-RFLP analysis of the $A L D H 2$ polymorphism was performed and patients were divided into two groups based on their enzymatic activity: those homozygous for the active alleles $(A L D H 2-1 / 2-1)$ and those with an inactive allele ( $A L D H 2-1 / 2-2$ or $A L D H 2-2 / 2-2$ ) (fig 4). Fifteen of 31 head and neck cancer patients $(48 \%)$ had the mutant $A L D H 2$ allele. The allelic frequency of the mutant $A L D H 2$ allele in head and neck cancer patients was comparable with that in the normal Japanese population. ${ }^{21-24}$ All patients,

Table 2 Genetic polymorphisms of alcohol metabolising enzymes and multiple Lugol voiding lesions (LVL) in head and neck cancer patients

\begin{tabular}{|c|c|c|c|c|c|}
\hline & \multicolumn{2}{|c|}{ Multiple LVL } & \multirow[b]{2}{*}{ p Value } & \multirow[b]{2}{*}{ OR } & \multirow[b]{2}{*}{$95 \% C I$} \\
\hline & Without & With & & & \\
\hline \multicolumn{6}{|l|}{$\mathrm{ADH} 3$ polymorphism } \\
\hline $\mathrm{ADH} 3^{1-1}$ & 12 & 15 & & & \\
\hline $\mathrm{ADH} 3^{1-2}$ or $\mathrm{ADH} 3^{2-2}$ & 2 & 2 & 0.622 & 0.8 & $0.1-6.5$ \\
\hline \multicolumn{6}{|l|}{ ALDH2 polymorphism } \\
\hline ALDH2-1/2-1 & 10 & 6 & & & \\
\hline ALDH $2-1 / 2-2$ or ALDH2-2/2-2 & 4 & 11 & $<0.05$ & 4.6 & $1.0-21.1$ \\
\hline
\end{tabular}

$\mathrm{ADH} 3$, alcohol dehydrogenase 3; ALDH2, aldehyde dehydrogenase 2 .

OR, odds ratio; $95 \%$ CI, $95 \%$ confidence interval.

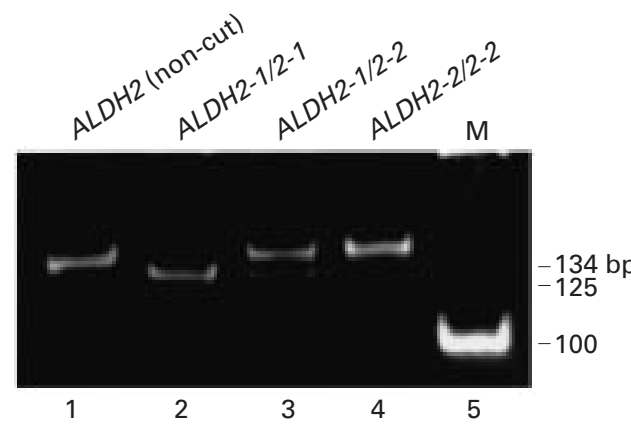

Figure 4 Representative electrophoretic pattern of the ALDH2 genotype analysed by polymerase chain reaction-restriction fragment length polymorphism (PCR-RFLP) from three patients with ALDH2-1/2-1, ALDH2-1/2-2, and ALDH2-2/2-2 genotypes. The ALDH2-1 allele yielded a $125 \mathrm{bp}$ fragment and the ALDH2-2 allele appeared as a 134 bp fragment. The undigested PCR product for ALDH2 (ALDH2 non-cut) is shown for comparison (lane 1). A $100 \mathrm{bp}$ marker ladder served as a reference for DNA fragment size (M, lane 5).

except for one with a mutant $A L D H 2$ allele, were heterozygotes.

Sixty five per cent $(11 / 17)$ of patients with multiple LVL had the mutant $A L D H 2$ allele whereas $71 \%(10 / 14)$ of those without multiple LVL were $A L D H 2-1$ homozygotes (p<0.05; OR 4.6, 95\% CI 1.0-21.1) (table 2). These results indicate that a mutant $A L D H 2$ allele is significantly associated with multiple LVL in head and neck cancer patients.

\section{ASSOCIATION OF OTHER VARIABLES WITH} MULTIPLE LVL

All 17 patients with multiple LVL were male smokers whereas the 14 patients without multiple LVL included four non-smokers and four women. To discriminate between the influence of smoking habit and sex predominance in this analysis, we also calculated ORs for multiple LVL in patients with the mutant $A L D H 2$ gene using the subgroups smokers and males. The observed ORs in smokers and males were 4.3 (95\% CI 0.8-22.9) and 7.3 (95\% CI $1.2-$ 46.2), respectively, and were similar to the OR in all patients, as described above.

To determine the involvement of other genetic factors in the development of multiple LVL, we compared the family history of cancer between patients with and without multiple LVL (table 1). The incidence of a family history of cancer was not different between the two groups. Hence we can partly exclude the possibility that patients with multiple LVL have germline or somatic mutations in oncogenes or antioncogenes.

\section{Discussion}

In this study we assessed the correlation between multiple LVL and genetic polymorphism of alcohol metabolising enzymes in patients with head and neck cancer. The prevalence of the mutant $A L D H 2$ allele in patients with multiple LVL was greater than in those without multiple LVL. However, there was no significant association with the $A D H 3$ polymorphism, in contrast with that reported previously in Western populations in head and neck cancer. ${ }^{15}$ 
In head and neck cancer patients, we frequently observed multiple LVL in the oesophagus using the endoscopic Lugol staining method. Our study showed that 17 of 31 head and neck cancer patients (55\%) had multiple LVL in the oesophagus. Shiozaki et al also reported the presence of multiple oesophageal Lugol unstained lesions in head and neck cancer patients. ${ }^{19}$ Furthermore, in our study, patients with multiple LVL, which consist mainly of squamous epithelial dysplasia, frequently had a second primary oesophageal cancer. As squamous epithelial dysplasia is considered a premalignant lesion of squamous cell carcinoma, ${ }^{1-3}$ it is highly likely that the presence of multiple LVL is a predisposing condition for the development of a second primary oesophageal cancer in patients with head and neck cancer. Therefore, the presence of multiple LVL strongly suggests that genetic and/or environmental factors provoke these premalignant and malignant changes throughout the oesophageal mucosa in head and neck cancer patients. ${ }^{25}$

Nakanishi et al showed that alcohol consumption was correlated with a higher incidence of small Lugol unstained lesions in the mucosa surrounding resected oesophageal cancer. ${ }^{5}$ Our limited study indicated that having the mutated $A L D H 2$ allele, rather than the amount of alcohol consumed per se, was more strongly associated with multiple LVL in head and neck cancer patients. ALDH2 is responsible for eliminating most of the acetaldehyde produced during metabolism of alcohol. Even in ALDH2-1/2-2 heterozygotes, blood acetaldehyde concentrations after drinking are approximately six times greater than those in $A L D H 2-1 / 2-1$ homozygotes. ${ }^{26}$ As acetaldehyde is a carcinogen ${ }^{12}$ that induces nasopharyngeal cancer in experimental animal models, ${ }^{27}$ this raises the possibility that severe systemic acetaldehydaemia may predispose the entire mucosa of the oesophagus to develop multiple LVL.

However, it is still not known why systemic accumulation of acetaldehyde is associated with cancer of the oesophagus but not other organs, such as the cervix. One possibility is that local $\mathrm{ADH}$ and $\mathrm{ALDH}$ activities may influence regional concentrations of acetaldehyde. One study demonstrated high ADH and low ALDH activities in the oesophageal mucosa. ${ }^{28}$ This suggests that intracellular acetaldehyde may accumulate locally during alcohol ingestion. This may be one reason why the incidence of squamous cell carcinoma in other tissues did not increase after consumption of alcohol. Further studies are needed to elucidate the contribution of local and systemic acetaldehyde accumulation to the development of multiple LVL.

The effect of smoking on the development of multiple LVL in patients with head and neck cancer remains inconclusive as almost all patients in this study smoked. Even when nonsmokers were excluded the statistical analysis showed negligible differences. Therefore, in this analysis, smoking did not affect the association between the mutant $A L D H 2$ allele and multiple LVL, while smoking is a definite risk factor for multiple occurrence of cancers in the upper aerodigestive tract. ${ }^{10} \mathrm{~A}$ further large scale study is needed to elucidate this issue.

In conclusion, our findings indicate that the mutant $A L D H 2$ allele is closely associated with the development of multiple LVL in head and neck cancer patients. It would be interesting to determine if multiple LVL are observed in Western populations that lack the mutant $A L D H 2$ allele. This would help us to understand to what extent the mutant $A L D H 2$ allele is responsible for the development of multiple LVL.

We are very grateful to Dr Satoshi Sasaki for helpful advice and discussion. This work was supported in part by grants-in-aid for cancer research (10-25 and 10-36) and a grant for the Second term Comprehensive 10-year Strategy for Cancer Control from the Ministry of Health and Welfare of Japan.

1 Henson DE, Albores SJ. The pathology of incipient neoplasia. Philadelphia: WB Saunders, 1986.

2 Kitamura K, Kuwano H, Yasuda M, et al. What is the earliest malignant lesion in the esophagus? Cancer 1996;77: 1614-19.

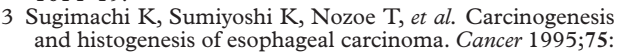
$1440-5$.

4 Mori M, Adachi Y, Matsushima T, et al. Lugol staining pattern and histology of esophageal lesions. Am F Gastroenterol 1993;88:701-5.

5 Nakanishi Y, Ochiai A, Yoshimura K, et al. The clinicopathological significance of small areas unstained by Lugol's iodine in the mucosa surrounding resected esophageal carcinoma: an analysis of 147 cases. Cancer 1998;82: 1454-9.

6 Shimada M, Horii A, Sasaki S, et al. Infrequent replication errors at microsatellite loci in tumors of patients with muliple primary cancers of the esophagus and various other tissues. Fpn f Cancer Res 1995;86:511-15.

7 Birch JM, Blair V, Kelsey AM, et al. Cancer phenotype correlates with constitutional TP53 genotype in families with the Li-Fraumeni syndrome. Oncogene 1998;17:1061-8.

8 Hisada M, Garber JE, Fung CY, et al. Multiple primary cancers in families with Li-Fraumeni syndrome. $\mathcal{F}$ Natl Cancer Inst 1998;90:606-11.

9 Morita M, Kuwano H, Ohno S, et al. Multiple occurrence of carcinoma in the upper aerodigestive tract associated with esophageal cancer: reference to smoking, drinking and family history. Int $\mathcal{F}$ Cancer 1994;58:207-10.

10 Day GL, Blot WJ, Shore RE, et al. Second cancers following oral and pharyngeal cancers: role of tobacco and alcohol. $\mathcal{F}$ Natl Cancer Inst 1994;86:131-7.

11 Alcohol drinking. In: IARC monographs on the evaluation of the carcinogenic risk to human. Lyon: International Agency the carcinogenic risk to human. Lyon: International

12 Allyl compounds, aldehydes, epoxides and peroxides. In: IARC monographs on the evaluation of the carcinogenic risk of IARC monographs on the evaluation of the carcinogenic risk of
chemicals to human. Lyon: International Agency for

13 Homann N, Karkkainen P, Koivisto, et al. Effect of acetaldehyde on cell regeneration and differentiation of the upper gastrointestinal tract mucosa. F Natl Cancer Inst 1997;89:1692-7.

14 Bosron WF, Li TK. Genetic polymorphism of human liver alcohol and aldehyde dehydrogenases, and their relationship to alcohol metabolism and alcoholism. Hepatology 1986;6:502-10

15 Harty LC, Caporaso NE, Hayes RB, et al. Alcohol dehydrogenase 3 genotype and risk of oral cavity and pharyngeal cancers. F Natl Cancer Inst 1997;89:1698-705.

16 Agarwal DP, Goedde HW. Pharmacogenetics of alcohol metabolism and alcoholism. Pharmacogenetics 1992;2:4862 .

17 Yokoyama A, Muramatsu T, Ohmori T, et al. Multiple primary esophageal and concurrent upper aerodigestive tract cancer and the aldehyde dehydrogenase-2 genotype of Japanese alcoholics. Cancer 1996;77:1986-90.

18 Yokoyama A, Muramatsu T, Ohmori T, et al. Alcoholrelated cancers and aldehyde dehydrogenase- 2 in Japanese alcoholics. Carcinogenesis 1998;19:1383-7.

19 Shiozaki H, Tahara H, Kobayashi K, et al. Endoscopic screening of early esophageal cancer with the Lugol dye method in patients with head and neck cancers. Cancer 1990;66:2068-71.

20 Groppi A, Begueret J, Iron A. Improved methods for genotype determination of human alcohol dehydrogenase (ADH) at $A D H 2$ and $A D H 3$ loci by using polymerase chain reactiondirected mutagenesis. Clin Chem 1990;36:1765-8.

21 Harada S, Zhang S. New strategy for detection of ALDH2 mutant. Alcohol Alcohol 1993;28:11-13.

22 Harada S, Misawa S, Agarwal DP, et al. Liver alcohol dehydrogenase and aldehyde dehydrogenase in the Japanese: drogenase and aldehyde dehydrogenase in the Japanese:
isozyme variation and its possible role in alcohol intoxication. Am f Hum Genet 1980;32:8-15.
tion. 
23 Smith $M$. Genetics of human alcohol aldehyde dehydrogenases. Adv Hum Genet 1986;15:249-90.

24 Hori H, Kawano T, Endo M, et al. Genetic polymorphisms of toabacco- and alcohol-related metabolizing enzymes and human esophageal squamous cell carcinoma susceptibility. f Clin Gastroenterol 1997;25:568-75.

25 Slaughter DP, Southwick HW, Smejkal W. "Field cancerization" in oral stratified squamous epithelium: clinical implications of multicentric origin. Cancer 1953;6:963-8.

26 Yamamoto K, Ueno Y, Mizoi Y, et al. Genetic polymorphism of alcohol and aldehyde dehydrogenase and the effects on alcohol metabolism. Arukoru Kenkyuto Yakubutsu Ison 1993;28:13-25.

27 Feron VJ, Kruysse A, Woutersen RA. Respiratory tract tumors in hamsters exposed to acetaldehyde vapour alone or simultaneously to benzo[a] pyrene or diethylnitrosamine. Eur $\mathcal{F}$ Cancer Clin Oncol 1982;18:13-31.

28 Yin SJ, Chou FJ, Chao SF, et al. Alcohol and aldehyde dehydrogenases in the human esophagus: comparison with the stomach enzyme activities. Alcohol Clin Exp Res 1993;17: 376-81. 